\section{Estudo \\ Ecibate}

em Testã⿻

Dlanejamento
Revista Estudo \& Debate, Lajeado, v. 26, n. 2, 2019. ISSN 1983-036X

DOI: http://dx.doi.org/10.22410/issn.1983-036X.v26i2a2019.1989

\title{
ENQUADRAMENTO DAS CONTAS PÚBLICAS MUNICIPAIS A PARTIR DOS PRESSUPOSTOS DA LÓGICA FUZZY
}

\author{
Ari Söthe ${ }^{1}$, Rodrigo Prante Dill ${ }^{2}$
}

\begin{abstract}
Resumo: Este estudo busca propor um modelo baseado na lógica fuzzy para avaliar o enquadramento de contas municipais aos limites fiscais. Utilizou-se como variáveis para a construção do modelo a destinação de recursos públicos municipais que interferem na decisão de aprovação ou reprovação das contas. $\mathrm{O}$ modelo é composto de sete entradas, um conjunto de regras de inferência e uma saída discreta para a avaliação das contas públicas. Foram realizadas simulações das contas públicas de municípios de acordo com o estabelecido na legislação. Os resultados indicam as potencialidades oferecidas pelo modelo. Por possibilitar um sistema de avaliação que vai além das restrições impostas pela lógica binária, na qual as contas de uma prefeitura são aprovadas ou reprovadas, sem qualquer possibilidade de transição entre uma ou outra. Por permitir ao analista de contas públicas configurar o software, por meio de percentual por ele atribuído aos limites, de modo que o mesmo seja mais brando ou rígido com os limites não atingidos e/ou ultrapassados pelos gestores públicos. Pela capacidade do sistema, pode ser utilizado como ferramenta de auxílio aos gestores públicos municipais para que se enquadrem com antecedência nos limites previstos na legislação. Por fim, o presente estudo pode contribuir para a ciência contábil na área da contabilidade pública, à medida que procurou demonstrar a aplicação de um modelo que não repousa sobre a lógica clássica.
\end{abstract}

Palavras-chave: Lógica fuzzy. Limites fiscais. Municípios.

\section{MUNICIPAL PUBLIC ACCOUNTS FRAMEWORK FROM FUZZY LOGIC ASSUMPTIONS}

\begin{abstract}
This study aims to propose a model based on fuzzy logic to evaluate the framing of municipal accounts to fiscal limits. We used as variables for the construction of the model the allocation of municipal public resources that interfere in the decision of approval or disapproval of the accounts. The model consists of seven inputs, a set of inference rules and a discrete output for the evaluation of public accounts. Simulations of the public accounts of municipalities were carried out according to the established in the legislation. The results indicate the potential offered by the model. By enabling an evaluation system that goes beyond the constraints imposed by binary logic, where the accounts of a city hall are approved or disapproved, without any possibility
\end{abstract}

1 Doutor em Desenvolvimento Regional pela Universidade Regional de Blumenau - FURB, Mestre em Ciências Contábeis pela Universidade Regional de Blumenau - FURB, Professor da Universidade Federal da Fronteira Sul - UFFS;

2 Mestre em Administração pela Universidade Federal de Santa Catarina - UFSC, Professor da Universidade Federal da Fronteira Sul - UFFS. 
of transition between one or the other. For allowing the public accounts analyst to configure the software, by means of a percentage assigned by the software to the limits, so that it is more lenient or rigid with the limits not reached and / or exceeded by public managers. Due to the capacity of the system, it can be used as a tool to help municipal public managers to fit in advance within the limits established in the legislation. Finally, the present study may contribute to accounting science in the area of public accounting, as it sought to demonstrate the application of a model that does not rest on classical logic.

Keywords: Fuzzy logic. Fiscal limits. Municipalities.

\section{INTRODUÇÃO}

Ao que tudo indica, a lógica nasceu dos esforços dos pensadores da Grécia Antiga empenhados em analisar as estruturas dos raciocínios, organizando-os e classificando-os. O filósofo grego Aristóteles (384-322 A.C.) e outros defendiam o uso da lógica como poderoso instrumento para se alcançarem conhecimentos científicos, seguros, metódicos e sistemáticos em qualquer campo da atividade humana (DILL; COSTA JR; SANTOS, 2014).

Em sua visão da lógica, Aristóteles entendia que as proposições podiam ter apenas dois valores de verdade: verdadeiro ou falso. Entre outros princípios, em sua formulação não cabe, por exemplo, contradições verdadeiras: uma proposição e sua negação serem simultaneamente verdadeiras (princípio da não-contradição). Também, entre duas proposiçóes contraditórias, uma deve ser falsa (princípio do terceiro excluído) (DILL; COSTA JR; SANTOS, 2013). É a visão da chamada lógica clássica, também denominada como binária ou booleana, da qual se falará com um pouco mais de detalhes.

Contemporaneamente, os personagens associados com essa ciência são, principalmente, George Boole (1815-1864), razão de ser da expressão "lógica booleana", e Augusto de Morgam (1807-1871), que contribuiu, principalmente, no que se chama de lógicas com tendências algébricas. Esses filósofos, quase que simultaneamente, criaram a denominada álgebra da lógica. $\mathrm{O}$ formato da lógica moderna decorreu das ideias de Gottlob Frege (1848-1925), com o desenvolvimento da lógica de predicado e com a forma atual da teoria da quantificação, que teve alguns aspectos aperfeiçoados por Bertrand Russel (18721970).

Após a publicação, entre 1910 e 1913, do livro Principia Mathematica, escrito por Bertrand Russel e Alfred North Whitehead (1861-1947), muitos outros filósofos, lógicos e matemáticos deram consideráveis contribuições para o desenvolvimento da lógica. Pode-se destacar Norbert Wiener (1894-1931), Rudolf Carnap (1891-1970), Jacques Herbrand (1908-1931), David Hilbert (1863-1943), John von Neumann (1903-1957), Wilhelm Ackerman (1896-1962), Clarence Iving Lewis (1883-1964), Luitzen Egbertus Jon Brouwer (1881-1966), entre outros.

Após todos os desenvolvimentos sofridos pela lógica, principalmente nos últimos dois séculos. Classifica-se as lógicas em clássica e não-clássica e estas em complementares da clássica e rivais da clássica ou heterodoxas. Considerando-se que este é um trabalho de aplicação da lógica em Contabilidade, permitir-se-ão algumas imprecisóes para tornar mais intuitivo e assimilável para o leitor a compreensão de alguns conceitos elementares. 
A lógica clássica é considerada binária, isto é, uma declaração é falsa ou verdadeira, não podendo ser ao mesmo tempo parcialmente verdadeira e parcialmente falsa. Neste tipo de lógica, certa afirmação ou é verdadeira ou é falsa. Nada existe entre o verdadeiro e o falso: chover, não chover, aceso ou apagado. Na lógica clássica há limites bruscos, pontualmente definidos entre os elementos que pertencem e os que não pertencem (ANTUNES, 2006). Seja tomado como exemplo um cidadáo com mais de 60 anos e outro com 80 anos. Pela legislação brasileira, ambos são considerados idosos, pois se enquadram no Estatuto do Idoso. Pela lógica clássica, um cidadão com 61 anos é considerado idoso. Todavia, essa mesma lógica considera que outro cidadáo com 59 anos e 11 meses náo é idoso, pelo contrário, deve ser considerada uma pessoa adulta.

Porém, em certos momentos, afirmaçóes envolvendo somente verdadeiro ou falso, não fazem sentido. Nem todas as situaçôes podem ser classificadas simplesmente como verdadeiras ou falsas. Quando se quer precisão para descrever algo, fica difícil estabelecer limites que permitam afirmativas ou negativas a respeito de qualidade das coisas. Quase sempre os limites entre o falso e verdadeiro são indefinidos, incertos, ambíguos e até mesmo contraditórios. Para dar uma resposta mais satisfatória a problemas relacionados com situaçóes não cobertas pela lógica clássica foram desenvolvidas as lógicas denominadas nãoclássicas (BORBA; DILL, 2007).

Dentre as lógicas não-clássicas, se destaca a lógica fuzzy, também conhecida como lógica nebulosa, em que o primeiro estudo foi publicado em 1965, pelo professor Lotfi Zadeh, que tratava dos conjuntos não totalmente verdadeiros nem tampouco totalmente falsos. Após seminal estudo, a lógica fuzzy teve crescente aplicação no mundo em diferentes campos do conhecimento. Na Contabilidade, por sua vez, estudos como de (COOLEY; HICKS, 1983, CHESLEY, 1986; ZEBDA, 1984, 1991; SIEGEL; KORVIN; OMER; ZEBDA, 1995, DESHMUKH; ROMINE, 1997, BOJADZIEV; BOJADZIEV, 1997, KORVIN; STRAWSER; SIEGEL, 1998, SIEGEL; KORVIN; OMER, 1998, DESHMUKH; TALLURU, 1998, FRIEDLOB; SCHLEIFER, 1999, SYAU; HSIEH; LEE, 2001, LIN; HWANG; BECKER, 2003, SERGUIEVA; HUNTER, 2004, ANTUNES, 2006, BORBA; DILL, 2007, LIN; LIN; HSIAO; LIN, 2009, COMUNALE; ROSNER; SEXTON, 2010, SAI, 2011, HAJIHAA, 2011, DILL; COSTA JR; SANTOS, 2013). No entanto, no campo da contabilidade pública nenhum trabalho foi encontrado nas bases de dados pesquisadas da CAPES e SCIELO. Em parte, essa ausência pode ser explicada por esta área ser regida por conjuntos de leis elaboradas para fins específicos de controle público.

Todavia, estudos inovadores representam um contraste ao modo tradicional do registro, evidenciação e avaliação dos resultados apresentados pela contabilidade. Merece destaque o estudo de Slomski (1996) que apresentou como nova forma de evidenciação no setor público a Demonstração do Resultado Econômico, sendo normatizada essa demonstração por meio da Resolução CFC no $1.133 / 08$. Söthe (2009) que avaliou o impacto produzido pela alteração do regime misto para regime de competência nos indicadores fiscais de despesas com pessoal, educação e saúde dos municípios. Independente dos aspectos legais definidos pela Constituição Federal, o estudo serviu para avaliar as efetivas despesas em funçâo de elementos como provisóes e deferimentos. 
O conjunto de leis que rege e regulamenta a Contabilidade Pública no Brasil encontra-se assentada sobre os pressupostos da lógica clássica e até mesmo estudiosos do Direito tem proposto interpretações utilizando como sustentáculo as lógicas não-classicas. Neste contexto, entre outras leis, a Lei de Responsabilidade Fiscal, que regulamenta e limita os gastos efetuados pelos municípios brasileiros, também utiliza como sustentáculo a lógica clássica. Ressalta-se que o não cumprimento destes limites, incorre numa série de limitaçóes aos municípios, tais como rejeição das contas, inelegibilidade, reclusão, detenção ou pagamento de multa dos gestores dos órgãos da administraçáo pública.

Diante disto, este estudo procura inovar ao propor um modelo baseado na lógica fuzzy para avaliar o enquadramento de contas municipais aos limites fiscais.

\section{REFERENCIAL TEÓRICO}

\subsection{Prestação de contas, transparência e limites legais}

A prestação de contas anteriormente à normatização estabelecida pelos órgãos fiscalizadores busca atender a necessidade da transparência dos atos do gestor (agente), diante do cidadão (principal) para eliminar a assimetria da informação existente (SÖTHE, 2009).

Diante disso, Slomski (2001) destaca que "na contabilidade pública, é, certamente, onde mais deve estar presente a filosofia da accountability (dever de prestar contas), pois, quando a sociedade elege seus representantes, espera que os mesmos ajam em seu nome, de forma correta, e que prestem contas de seus atos".

Assim a contabilidade pública serve "como uma técnica capaz de produzir, com oportunidade e fidedignidade, relatórios que sirvam à administração no processo de tomada de decisão e de controle de seus atos, demonstrando, por fim, os efeitos produzidos por esses atos de gestão no patrimônio da entidade" (KOHAMA, 2003). Complementarmente deverá atender o que estabelece a legislação, principalmente o que estabelece a Constituição Federal e sua legislação complementar como a Lei Complementar n 101/2000 (Lei de Responsabilidade Fiscal - LRF) que cita em seu art. 48.

\footnotetext{
Art. 48. São instrumentos de transparência da gestão fiscal, aos quais será dada ampla divulgaçáo, inclusive em meios eletrônicos de acesso público: os planos, orçamentos e leis de diretrizes orçamentárias; as prestações de contas e o respectivo parecer prévio; o Relatório Resumido da Execução Orçamentária e o Relatório de Gestão Fiscal; e as versōes simplificadas desses documentos.

Parágrafo único. A transparência será assegurada também mediante incentivo à participação popular e realização de audiências públicas, durante os processos de elaboraçáo e de discussão dos planos, lei de diretrizes orçamentárias e orçamentos.
}

Os Relatórios de Gestão Fiscal (RGF) e execução orçamentária servem de apoio à gestão, prestação de contas aos órgãos de controle externo como o poder legislativo, tribunal de contas e demais entidades e cidadãos que apreciam as contas dos entes públicos. 
De acordo com o artigo 55 da LRF, o RGF deve demonstrar: "1) o comparativo dos limites de despesa com pessoal, dívidas, concessão de garantias, operações de crédito e medidas corretivas quando ultrapassa algum dos limites; 2) a disponibilidades de caixa; inscrição em Restos a Pagar”.

De outro modo, o Relatório Resumido de Execução (RREO) demonstrará:

1) as receitas por fonte e categoria econômica; 2) as despesas por grupo de natureza e categoria econômica; 3) as despesas, por função e subfunção; 4) a apuração da receita corrente líquida; 5) as receitas e despesas previdenciárias; 6) o resultado nominal e primário; 7) as despesas com juros; 8) os restos a pagar; 9) as projeçóes atuariais dos regimes de previdência social; 10) a variação patrimonial.

A prestação de contas, no entanto, não se resume aos relatórios exigidos pela legislação, mas por todos os instrumentos que ampliam a transparência das açóes dos gestores e publicados voluntariamente, permitindo a comparação pelo cidadão dos resultados com o setor privado, sentindo-se confortável pela eficiência na gestão dos recursos públicos em curto prazo (SLOMSKI, 2005).

Dentro do que estabelece a LRF, a prestação de contas demonstra o planejamento e execução orçamentária, evidenciando se o gestor alcançou o que foi proposto nos instrumentos de planejamento. De outro modo, os limites fiscais estabelecidos pela legislação permitirão avaliar o gestor quanto ao atendimento das metas fiscais, como os gastos com pessoal, educação, saúde, dívida, serviços terceirizados, entre outros.

$\mathrm{Na}$ Tabela 1 estão apresentados alguns dos limites estabelecidos pela legislação e que devem ser cumpridos pelos gestores municipais.

Tabela 1: Limites Fiscais aplicados aos poderes legislativo e executivo municipal

\begin{tabular}{l|l|l}
\hline Limite & Descriçáo & Regulamentaçáo \\
\hline $\begin{array}{l}\text { Dívida Consolidada } \\
\text { Líquida }\end{array}$ & - Máximo de 120\% da RCL ${ }^{1}$. & $\begin{array}{l}\text { Art. 3 inc. II (Resolução } \\
\text { do Senado Federal n } \\
\text { 40/2001) }\end{array}$ \\
\hline $\begin{array}{l}\text { Despesa com } \\
\text { Legislativo }\end{array}$ & $\begin{array}{l}-8 \% \text { da RCL (municípios até 100.000 habitantes); } \\
-7 \% \text { da RCL (municípios entre 100.001 e 300.000 } \\
\text { habitantes); } \\
-6 \% \text { da RCL (municípios entre 300.001 e 500.000 } \\
\text { habitantes); } \\
-5 \% \text { da RCL (municípios com mais de 500.000 } \\
\text { habitantes). }\end{array}$ & Art. 29-A (CF/1988) \\
\hline $\begin{array}{l}\text { Despesa com } \\
\text { Manutençáo e } \\
\text { Ensenvolvimento do }\end{array}$ & $\begin{array}{l}\text { - Mínimo de 25\% da RCL os impostos e suas } \\
\text { transferências. }\end{array}$ & Art. 212 (CF/1988) \\
\hline $\begin{array}{l}\text { Despesa com Pessoal } \\
\text { Ensino }\end{array}$ & $\begin{array}{l}\text { - Máximo de 6\% da RCL }{ }^{1} \text { para o legislativo e } \\
\text { tribunal de contas do município; } \\
\text { - Máximo de 54\% da RCL para o executivo; }\end{array}$ & $\begin{array}{l}\text { Art. 20, inc. III, a, b (LRF } \\
- \text { LC nº 101/2000) }\end{array}$ \\
\hline
\end{tabular}




\begin{tabular}{l|l|l}
\hline Limite & Descriçáo & Regulamentaçáo \\
\hline $\begin{array}{l}\text { Despesa com } \\
\begin{array}{l}\text { Remuneração dos } \\
\text { Profissionais do } \\
\text { Magistério }\end{array}\end{array}$ & - Mínimo de 60\% do FUNDEB ${ }^{2 .}$ & Art. 60 (ADCT) \\
\hline Despesa com Saúde & $\begin{array}{l}\text { - Mínimo de 15\% dos impostos e suas } \\
\text { transferências. }\end{array}$ & Art. 77 (CF/1988) \\
\hline
\end{tabular}

Fonte: Adaptado da LC n 101/2000, CF/1988 e Resolução nº 40/2001.

${ }^{1} \mathrm{RCL}$ - Receita Corrente Líquida.

${ }^{2}$ FUNDEB - Fundo de Manutenção e Desenvolvimento da Educação Básica e de Valorização dos Profissionais da Educação.

A observação dos limites fiscais, estabelecidos pela Constituição Federal, LRF e Resoluçáo do Senado Federal, por parte dos gestores públicos municiais, é fundamental para o atendimento das áreas essenciais como a saúde e educação. Por outro lado, limites como da dívida, pessoal, serviços de terceiros e do poder legislativo ganham importância para evitar o endividamento e engessamento da máquina pública.

Desse modo, a falta de atendimento de qualquer desses limites fiscais é passível de emissão do parecer pela rejeição das contas dos gestores públicos municipais pelos tribunais de contas municipais ou estaduais. Nesse sentido, a lógica poderá ser útil não somente de avaliação dos limites fiscais, assim como, para a prevenção ao possível não cumprimento dos limites.

\subsection{Lógica fuzzy}

Controladores fuzzy são muito simples conceitualmente, pois consistem de um estágio de entrada (crisp - entradas discretas atreladas a algum tipo de escala numérica), um estágio de processamento e um estágio de saída. O estágio de entrada mapeia dados de entrada de maneira apropriada às funçôes consecutivas e valores verdadeiros. O estágio de processamento é aquele em que se procura alcançar a soluçáo para os problemas, podendo ser dividido em três passos básicos: fuzzificação, regras de avaliação e defuzzificação. Aqui é invocada cada regra adequada que gera um resultado para cada uma delas e, então, combinam-se os resultados dessas regras. Por último, tem-se um estágio de saída cujo resultado, já defuzzificado da operação, é colocado para dentro do sistema, executando um controle (saída crisp) (SHAW; SIMÓES, 2001).

A seguir serão apresentadas em detalhes os estágios (fuzzificação, funçôes de pertinência, regras de avaliação e defuzzificação) de um controlador fuzzy.

\subsubsection{Fuzzificação e Funçóes de Pertinência}

Fuzzificação é o processo de colocar nomes no universo de discurso de cada entrada crisp. O universo de discurso pode ser descrito como a faixa de valores associados a uma variável fuzzy, onde são definidos vários conjuntos fuzzy dentro de um universo de discurso, cada qual com o seu próprio domínio que sobrepóe com os domínios dos seus conjuntos 
fuzzy vizinhos. Ou seja, o universo de discurso se refere ao domínio que se dá a um determinado conjunto.

Pode-se tomar como exemplo a metodologia utilizada para classificação do porte de uma empresa em relaçáo ao número de funcionários, para mostrar como se estabelece o domínio de cada função de pertinência. Verifica-se, na Figura 1, que cada um dos conjuntos recebe um rótulo, ou seja, um nome: Pequena, Média e Grande.

Figura 1: Variáveis linguísticas

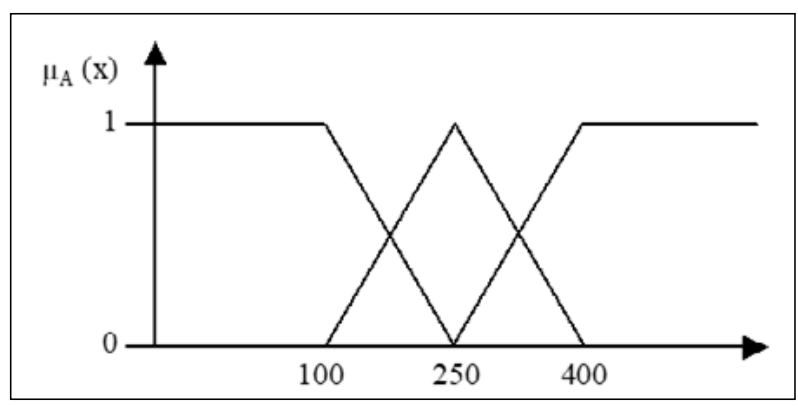

Fonte: Adaptado de Bojadziev e Bojadziev (1997).

Cada conjunto também recebe uma faixa de valores correspondendo ao nome que lhe foi dado. Este valor é chamado de grau de pertinência. Por exemplo, a condição "Média" obtém um domínio de 100 a 400 funcionários. No eixo vertical $(\mathrm{Y})$, podem-se verificar os valores referidos para os graus de pertinência das entradas crisp em cada conjunto fuzzy.

As funçōes de pertinência, também conhecidas como conjuntos fuzzy são, na verdade, funçóes matemáticas que fornecem um significado numérico para um conjunto fuzzy. A etapa de fuzzificação mapeia a entrada (um valor definido, ou crisp) entre valores de 0 a 1 , através das funçôes de pertinência, que é o grau de pertinência, mencionado anteriormente. As funções mais utilizadas são demonstradas no Quadro 1.

Quadro 1: Funções de pertinência fuzzy

\begin{tabular}{|c|c|}
\hline Triangular & Triângulo $(x, a, b, c)=\max \left(0, \min \left[\frac{(x-a)}{(b-a)}, \frac{(c-x)}{(c-b)}\right]\right)$ \\
\hline Trapezoidal & Trap $(x, a, b, c, d)=\max \left(0, \min \left[\frac{(x-a)}{(b-a)}, 1, \frac{(d-x)}{(d-c)}\right]\right)$ \\
\hline Gaussiana & Gaussiana $(x, s, c)=\exp \left\{\frac{-(x-c)}{s}\right\} 2$ \\
\hline Sigmoidal & Sig $(x, a, c)=\frac{1}{1+\exp [-a(x-c)]}$ \\
\hline
\end{tabular}

Fonte: Adaptado de Bojadziev e Bojadziev (1997). 


\subsubsection{Regras de Avaliaçáo}

O segundo passo do processo de controle fuzzy são as regras de avaliação. As regras fuzzy são declaraçôes SE - ENTÃO (IF-THEN) que descrevem a ação a ser feita em resposta a várias entradas fuzzy. Pode-se usar como exemplo um sistema de classificaçáo do perfil do investidor quanto à política de investimentos financeiros, onde uma das regras poderia ser a seguinte: $\mathbf{S E}$ a idade é Jovem E a Renda é Alta, ENTÃO o perfil de investimento é Arrojado. Em síntese, o formato das regras obedece ao seguinte padrão: SE (antecedente 1) E (antecedente 2)... ENTÁO (consequente 1).

Sistemas fuzzy baseados em regras traduzem expressões qualitativas, vagas e imprecisas, provenientes de observaçóes de especialistas. Tais regras possibilitam formulações que permitem controlar os sistemas em questáo (BOJADZIEV; BOJADZIEV,1997).

\subsubsection{Defuzzificação}

O sistema fuzzy, ao receber uma entrada, transforma-a em uma entrada fuzzy que, por sua vez, é submetida ao sistema de inferência (regras fuzzy) que devolve uma saída fuzzy para este sistema. Porém, em muitos casos, é desejável um valor numérico na saída. A defuzzificaçâao (apesar do nome) não é exatamente o processo inverso da fuzzificação. Diversos métodos têm sido propostos na literatura, entre os quais se pode destacar o Centro-da-Área, a Média-dos-Máximos e a Média-dos-Centros (VON ALTROCK, 1995). Na Figura 2 são resumidamente demonstrados os gráficos e fórmulas de cada um dos métodos citados.

Figura 2 - Métodos de defuzzificação

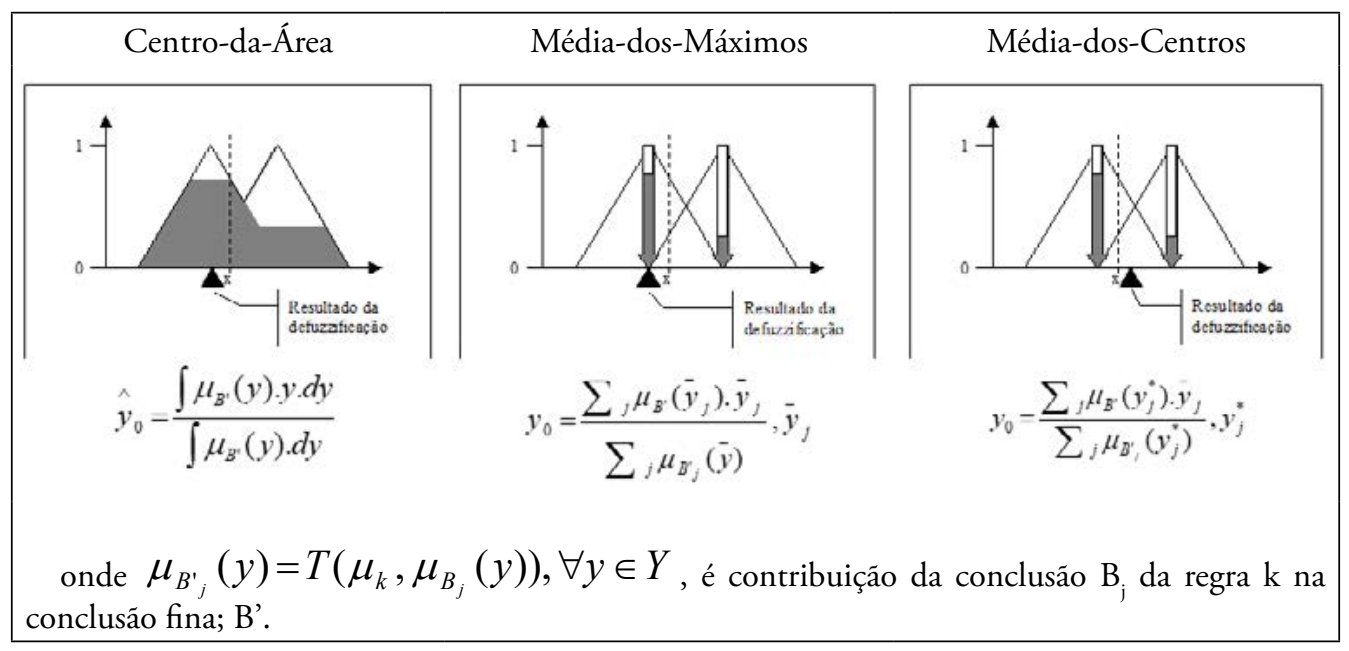

Fonte: Adaptado de Shaw e Simões (2001).

De acordo com Shaw e Simóes (2001) os métodos de defuzzificação podem descritos da seguinte forma: 
Centro-da-Área (C-o-A) - calcula o centróide da área composta pelo termo de saída fuzzy; esse termo de saída é composto pela união de todas as contribuiçôes de regras. O centróide é um ponto que divide a área em duas partes iguais.

Média-dos-Máximos (M-o-M) - uma abordagem para a defuzzificação pode ser a de se utilizar a saída cujo valor tenha o maior valor de pertinência. Essa abordagem também não funciona bem, devido à necessidade de se escolher qual o máximo utilizar.

Média-dos-Centros (C-o-M) - neste método os picos das funçôes de pertinência são usados, enquanto se ignoram as áreas das funções de pertinência; as contribuiçôes múltiplas de regras são consideradas por esse método. Os valores não nulos do vetor de possibilidades de saída são posicionados nos picos correspondentes. $\mathrm{O}$ valor de defuzzificação é determinado achando-se o ponto de apoio onde os pesos ficam equilibrados. Assim, as áreas das funções de pertinência não desempenham nenhum papel e apenas os máximos são usados.

De acordo com Borba e Dill (2007) diversos métodos têm sido propostos na literatura, entre os quais se pode destacar o centróide da área, a média dos máximos e a média dos centros, sendo o último, o método mais utilizado". Cabe ressaltar que a lógica fuzzy pode fazer uso de métodos alternativos a defuzzificação. Como os métodos Mandani e Sugeno, conforme destacam Andrade e Jaques (2008). Sendo que em seu estudo comparativo, os autores encontraram vantagens na adoção do método Sugeno.

\section{PROCEDIMENTOS METODOLÓGICOS}

Os dados para a construção do modelo correspondem as variáveis de destinação de recursos públicos municipais que interferem na decisão de aprovação ou reprovação das contas. A partir da legislação, as variáveis para essa decisão correspondem: Dívida Consolidada Líquida (DCL); Despesa com o Legislativo (DL); Despesa com Manutençáo e Desenvolvimento do Ensino (DMDE); Despesa com Pessoal (DP); Despesa com Pessoal do Legislativo (DPL); Despesa com Remuneração dos Profissionais do Magistério (DRPM) e Despesa com Saúde (DS). Em complemento, o modelo utiliza como base os limites máximos ou mínimos em percentuais da destinação dos recursos, assim como, os limites definidos pelo usuário do sistema.

\section{CONSTRUÇÁO DO MODELO E DISCUSSÁO}

Para a implementação de sistemas que envolvem lógica fuzzy, se faz necessário a utilização de software específico; dentre eles, destacam-se Fuzzy Calc ${ }^{\circ}$, Matlab ${ }^{\circ}$ e FuzzyTech ${ }^{\circ}$. Para este estudo, se optou por este último em sua versão demo, pois se trata de um software com recursos visuais e de fácil operação, mesmo para usuários que não estejam familiarizados com tais conceitos.

\subsection{Construçáo da árvore de decisóes}

O carregamento do sistema consiste em determinar a árvore de decisóes que o sistema utilizará, quais sejam, as variáveis linguísticas de entrada, as variáveis de saída, qual a escala de valores atribuída a cada variável, as regras de conduta e o tipo de método de implicaçáo e inferência que serão utilizados. 
Conforme a Figura 3, a árvore de decisóes do modelo proposto é composta por sete entradas (Dívida Consolidada Líquida - DCL, Despesa com o Legislativo - DL, Despesa com Manutenção e Desenvolvimento do Ensino - DMDE, Despesa com Pessoal - DP, Despesa com Pessoal do Legislativo - DPL, Despesa com Remuneração dos Profissionais do Magistério - DRPM e Despesa com Saúde - DS) e uma saída (Avaliação).

Figura 3: Árvore de decisões

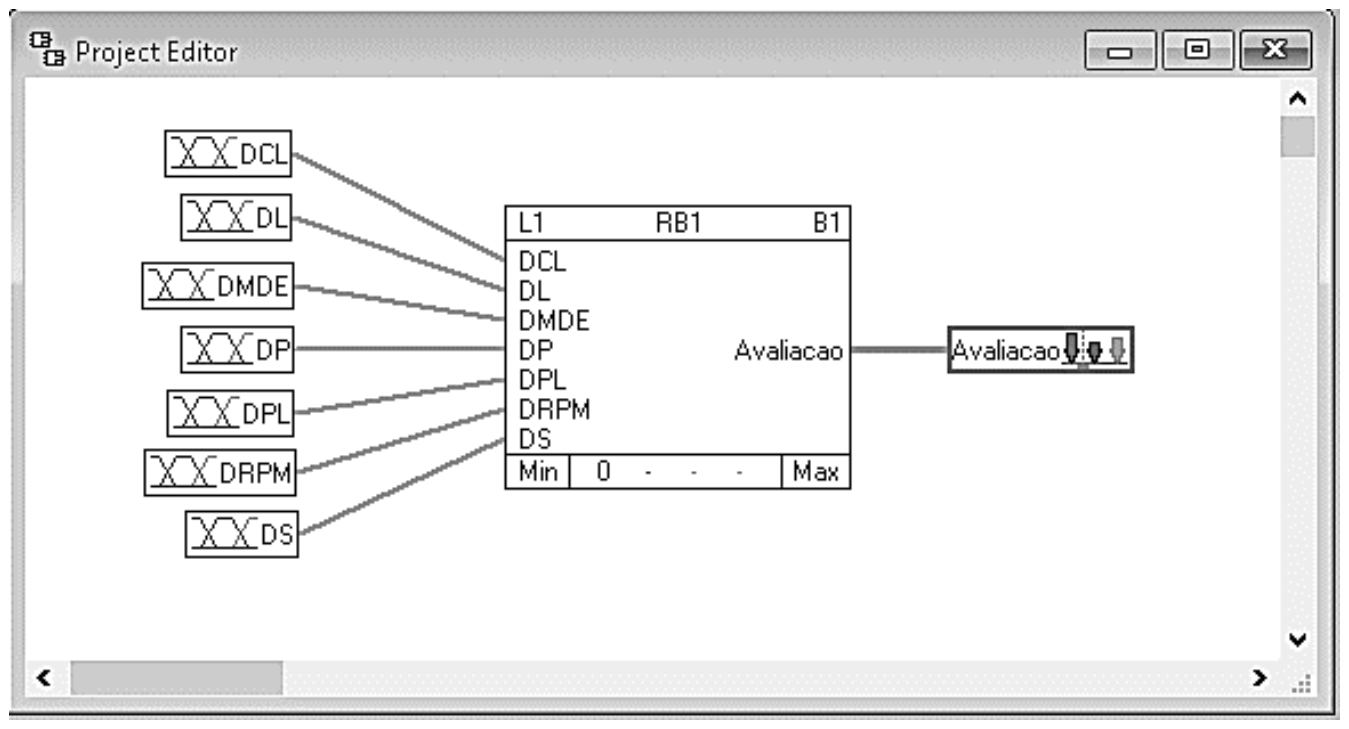

Fonte: Autores da pesquisa.

\subsection{Construçáo das variáveis de entrada (input) e saída (output)}

Cada variável de entrada recebeu dois termos qualitativos (Aprovado e Reprovado) de acordo com os limites fiscais. Cada conjunto recebeu uma faixa de valores correspondendo ao nome que lhe foi dado. Este valor é chamado de grau de pertinência.

Observando-se a Figura 4, verifica-se que o rótulo Aprovado possui grau de pertinência igual a um para qualquer valor igual ou menor a $120 \%$, deste valor a $132 \%$, pertinência decrescente até zero, e, pertinência igual a zero para qualquer valor acima de $132 \%$. O rótulo Reprovado possui grau de pertinência igual a zero para qualquer valor igual ou menor a $120 \%$, deste valor a $132 \%$, pertinência crescente até um, e, pertinência igual a um para qualquer valor acima do mesmo. 
Figura 4: Função fuzzy de entrada - Dívida Consolidada Líquida - DCL

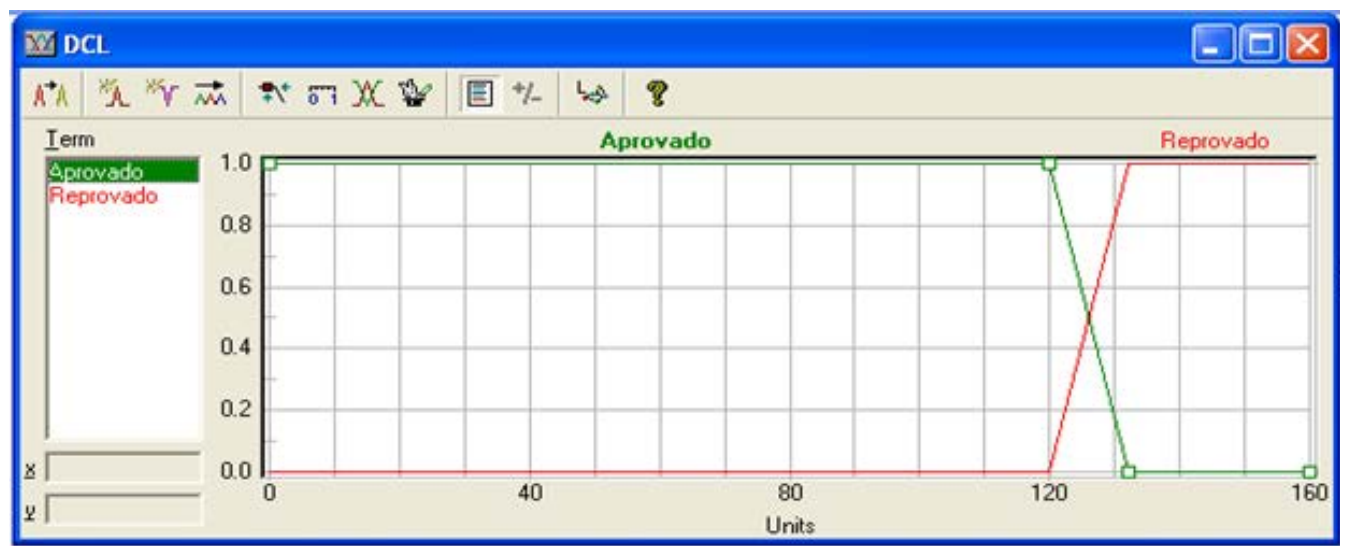

Fonte: Autores da pesquisa.

Ressalta-se que o valor de $120 \%$ é estabelecido pela legislação, enquanto que o valor de $132 \%$ foi arbitrariamente definido mediante o acréscimo de $10 \%$ no valor estabelecido em lei. Sendo esta uma importante possibilidade de modelos que utilizam a lógica fuzzy como pressuposto, pois permitem que especialistas e usuários do sistema definam, conforme suas necessidades, os graus de pertinência das variáveis. A Tabela 2 demonstra como cada variável de entrada foi inserida no sistema.

Tabela 2: Variáveis de entrada do sistema

\begin{tabular}{|c|c|c|c|}
\hline Elemento & Dispositivo legal & Limite estabelecido por lei & $\begin{array}{c}\text { Limite definido } \\
\text { pelo usuário }\end{array}$ \\
\hline $\begin{array}{l}\text { Dívida Consolidada } \\
\text { Líquida (DCL) }\end{array}$ & $\begin{array}{l}\text { Art. } 3 \text { inc. II (Resolução do } \\
\text { Senado Federal no 40/2001) }\end{array}$ & Máximo de $120 \%$ da RCL & $132 \%$ \\
\hline $\begin{array}{l}\text { Despesa com o Legislativo } \\
\text { (DL) }\end{array}$ & Art. 29-A (CF/1988) & $\begin{array}{l}\text { Máximo de } 8 \% \text { da RCL } \\
\text { (municípios com até cem } \\
\text { mil habitantes). }\end{array}$ & $8,8 \%$ \\
\hline $\begin{array}{c}\text { Despesa com Manutenção } \\
\text { e } \\
\text { Desenvolvimento do } \\
\text { Ensino (DMDE) }\end{array}$ & Art. $212(\mathrm{CF} / 1988)$ & $\begin{array}{l}\text { Mínimo de } 25 \% \text { das receitas } \\
\text { de impostos e transferências } \\
\text { constitucionais }\end{array}$ & $22,5 \%$ \\
\hline Despesa com Pessoal (DP) & 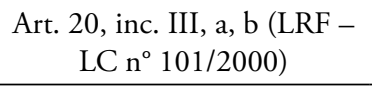 & Máximo de $54 \%$ da RCL & $59,4 \%$ \\
\hline $\begin{array}{c}\text { Despesa com Pessoal do } \\
\text { Legislativo (DPL) } \\
\end{array}$ & $\begin{array}{l}\text { Art. 20, inc.I, II e III do art. } \\
20\left(\mathrm{LRF}-\mathrm{LC}^{\circ} 101 / 2000\right)\end{array}$ & Máximo de $6 \%$ da RCL & $6,6 \%$ \\
\hline $\begin{array}{l}\text { Despesa com Remuneração } \\
\text { dos Profissionais do } \\
\text { Magistério (DRPM) }\end{array}$ & Art. 60 (ADCT) & $\begin{array}{l}\text { Mínimo de } 60 \% \text { do } \\
\text { FUNDEB na remuneraçáo } \\
\text { do magistério com } \\
\text { educaçáo infantil e ensino } \\
\text { fundamental }\end{array}$ & $54 \%$ \\
\hline
\end{tabular}




\begin{tabular}{cccc}
\hline Elemento & Dispositivo legal & Limite estabelecido por lei & $\begin{array}{c}\text { Limite definido } \\
\text { pelo usuário }\end{array}$ \\
\hline Despesa com saúde (DS) & Art. 77 (CF/1988) & $\begin{array}{c}\text { Mínimo de } 15 \% \text { das receitas } \\
\text { de impostos e transferências } \\
\text { constitucionais }\end{array}$ & $13,5 \%$ \\
\hline
\end{tabular}

Fonte: Autores da pesquisa.

A função fuzzy de saída recebeu, de forma análoga as funções de entrada, dois rótulos (Reprovado e Aprovado). Sendo que o primeiro rótulo possui grau de pertinência decrescente de zero até um e o segundo possui grau de pertinência crescente de zero a um.

\subsection{Regras de produçáo}

$\mathrm{Na}$ implementação do sistema foram utilizadas nove conjuntos de regras (Tabela 3), criadas automática pelo software. Sendo permitido que o usuário exclua, inclua ou limite as regras que deverão ser acionadas e as que deverão ser desprezadas. Também é possível atribuir grau de verdade a uma determinada regra para que o consequente seja gerado. Assim, se o grau de verdade for, por exemplo, “zero", a regra sequer será acionada. Por outro lado, o valor "um" indica que a regra tem $100 \%$ de força para gerar a ação consequente.

Tabela 3: Conjunto de regras

\begin{tabular}{ccccccccc}
\hline Regra & DCL & DL & DMDE & DP & DPL & DRPM & DS & Avaliaçáo \\
\hline 1 & Aprovado & Aprovado & Aprovado & Aprovado & Aprovado & Aprovado & Aprovado & Aprovado \\
2 & Reprovado & Reprovado & Reprovado & Reprovado & Reprovado & Reprovado & Reprovado & Reprovado \\
3 & Aprovado & Aprovado & Aprovado & Aprovado & Aprovado & Aprovado & Reprovado & Reprovado \\
4 & Aprovado & Aprovado & Aprovado & Aprovado & Aprovado & Reprovado & Aprovado & Reprovado \\
5 & Aprovado & Aprovado & Aprovado & Aprovado & Reprovado & Aprovado & Aprovado & Reprovado \\
6 & Aprovado & Aprovado & Aprovado & Reprovado & Aprovado & Aprovado & Aprovado & Reprovado \\
7 & Aprovado & Aprovado & Reprovado & Aprovado & Aprovado & Aprovado & Aprovado & Reprovado \\
8 & Aprovado & Reprovado & Aprovado & Aprovado & Aprovado & Aprovado & Aprovado & Reprovado \\
9 & Reprovado & Aprovado & Aprovado & Aprovado & Aprovado & Aprovado & Aprovado & Reprovado \\
\hline
\end{tabular}

Fonte: Autores da pesquisa.

\subsection{Saídas discretas e simulaçóes do modelo}

Completadas todas as etapas de construção do modelo, o sistema apresenta as saídas discretas. A Figura 5 exibe as entradas (Watch: Interactive Debug Mode) inseridas no sistema, as regras ativadas (Spreadsheets Rule Editor - RB1) e a saída discreta (Avaliação). Assim, supondo-se, como exemplo, contas de uma prefeitura que não ultrapassa e/ou atinge os limites estabelecidos em lei e compreendem a Dívida Consolidada Líquida (DCL) igual a $115 \%$, Despesa com o Legislativo (DL) igual a 7\%, Despesa com Manutenção e Desenvolvimento do Ensino (DMDE) igual a 33\%, Despesa com Pessoal (DP) igual a 50\%, Despesa com Pessoal do Legislativo (DPL) igual a 5\%, Despesa com Remuneração 
dos Profissionais do Magistério (DRPM) igual a 65\% e Despesa com Saúde (DS) igual a $16 \%$, o sistema retorna uma saída discreta para a "Avaliação" dessa prefeitura como igual a $\mathrm{um}^{3}$.

Figura 5: Simulação em que os limites encontram-se de acordo com LRF

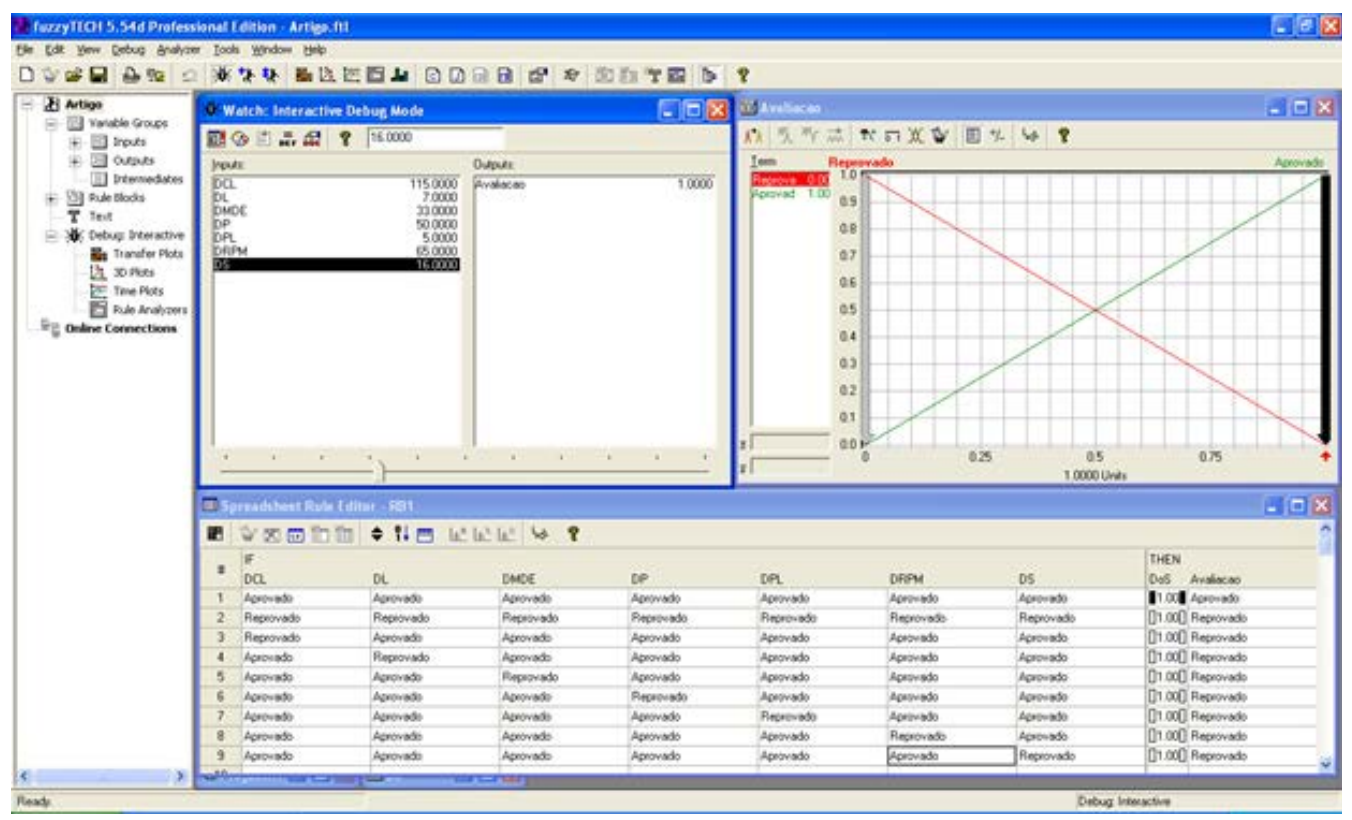

Fonte: Autores da pesquisa.

$\mathrm{Na}$ simulação anterior, se verifica que o sistema acionou apenas a primeira regra de inferência e a saída discreta foi igual a um, avaliando as contas dessa prefeitura como $100 \%$ aprovadas e $0 \%$ reprovadas. De modo óbvio, o resultado não poderia ser diferente, pois os valores inseridos no sistema simulam as contas de uma prefeitura que se encontra totalmente em acordo com os limites definidos em lei.

Considerando os mesmos valores anteriores, com exceção da Dívida Consolidada Líquida, demonstra-se na Figura 6 como o sistema avalia uma prefeitura que ultrapassa o limite previsto na LRF de sua Dívida Consolidada Liquida além dos 10\% acrescentados de margem no sistema, no caso, por um especialista. Verifica-se que somente a terceira regra é acionada e a saída discreta é igual a zero, avaliando as contas como $0 \%$ aprovadas e $100 \%$ reprovadas.

3 O método de defuzzificação utilizado foi a média-dos-centros. 
Figura 6: Simulação em que um limite é extrapolado

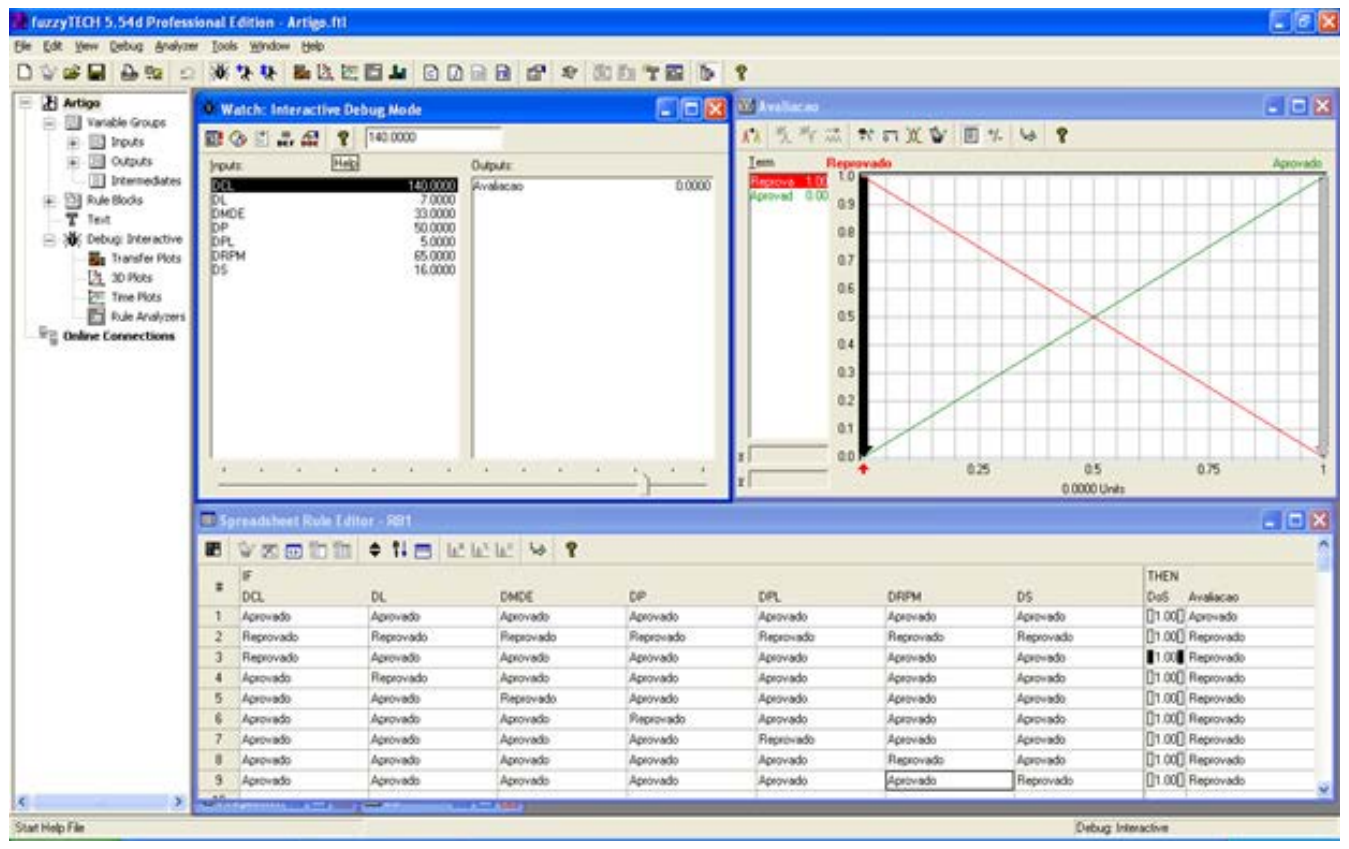

Fonte: Autores da pesquisa.

Pretende-se agora demonstrar a potencialidade do sistema em avaliar as contas de uma prefeitura que ultrapassa e/ou não atinge os limites estabelecidos em lei, mas não excede e/ou ultrapassa os limites de $10 \%$ estabelecidos no sistema. Essa região de transição, não mais brusca como preconiza a lógica clássica, e sim uma região onde ocorre transição gradual entre os critérios Aprovado e Reprovado, é denominada como "zona nebulosa". Assim, considerando os dados inseridos inicialmente e alterando a Dívida Consolidada Líquida para 125\%, Despesa com o Legislativo para 8,5\% e Despesa com Manutenção e Desenvolvimento do Ensino para 23\%, percebe-se na Figura 7 que o sistema ativa quatro conjuntos de regras $(1,3,4$ e 5) e retorna uma saída discreta de 0,2051 , avaliando as contas dessa prefeitura como $78 \%$ reprovadas e $20 \%$ reprovadas. 
Figura 7: Simulação em que os limites se situam na "zona nebulosa"

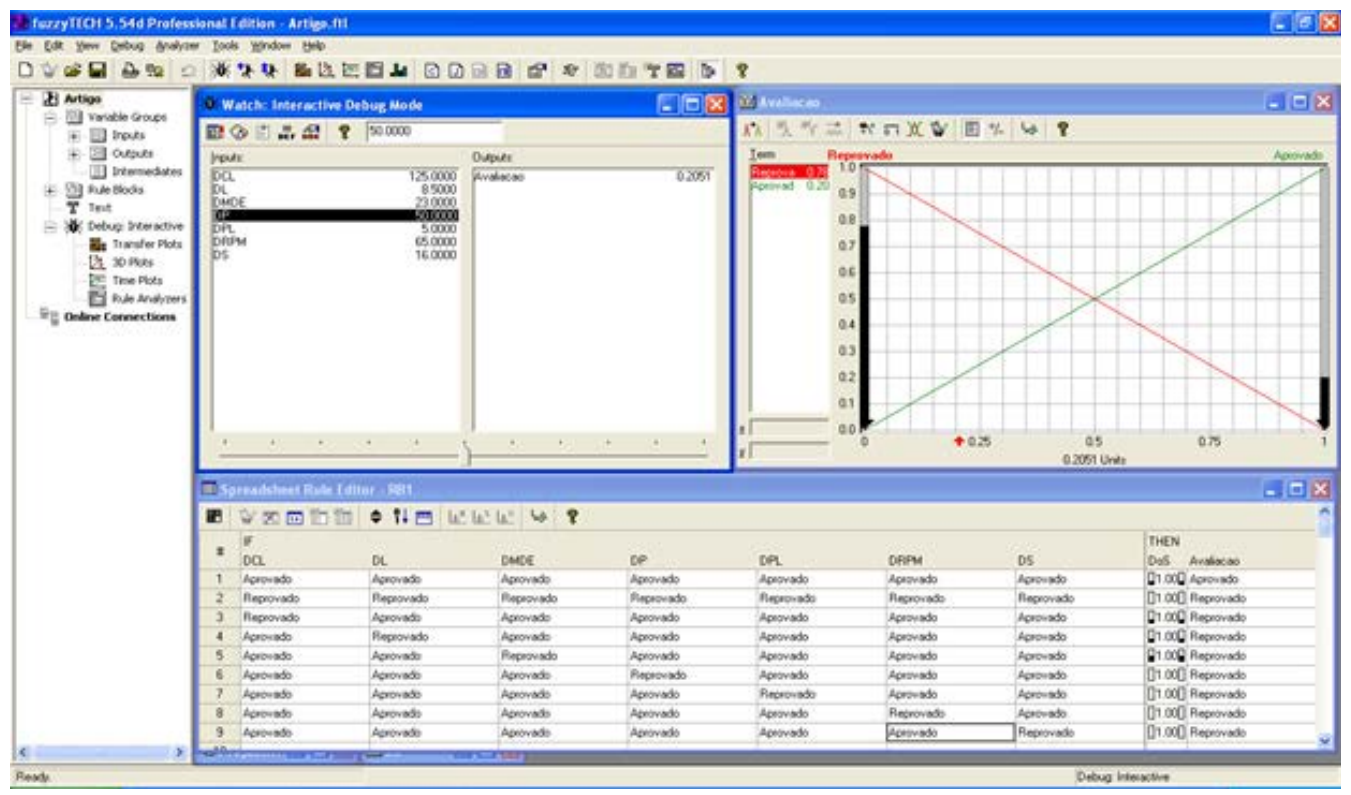

Fonte: Autores da pesquisa.

Diante das simulaçóes realizadas, o modelo se mostrou adequado para avaliar o enquadramento das contas públicas municipais a partir dos limites fiscais. Em complemento, ele ganha força, pois, a aprovação ou reprovação das contas municipais inclui também variáveis qualitativas que não foram objeto desse estudo, mas que podem ser determinantes na aprovaçáo ou rejeiçáo que a simples condiçáo de atender os limites fiscais dentro dos parâmetros inflexíveis definidos pela legislação.

\section{CONSIDERAÇÓES E RECOMENDAÇÓES FINAIS}

Este estudo buscou propor um modelo baseado na lógica fuzzy para avaliar o enquadramento de contas municipais aos limites fiscais. Este objetivo foi atingido. Ficou evidente nas simulaçóes realizadas as potencialidades oferecidas pelo modelo. Inicialmente, por possibilitar um sistema de avaliação que vai além das restriçóes impostas pela lógica binária, onde as contas de uma prefeitura são "aprovadas" ou "reprovadas", sem qualquer possibilidade de transição entre uma ou outra. Os modelos baseados na lógica clássica não possuem capacidade de discriminar prefeituras que excedem, por exemplo, o limite de $120 \%$ de sua Dívida Consolidada Líquida em $1 \%$ ou $300 \%$. Adicionalmente, destaca-se que o modelo proposto vai além das possibilidades restringentes da lógica clássica e parece ser mais adequado para simular a forma do raciocínio humano.

Adicionalmente, o sistema nebuloso permite, ao analista das contas públicas, configurar o software por meio de percentual por ele atribuído aos limites, de modo que o mesmo seja mais brando ou rígido com os limites náo atingidos e/ou ultrapassados pelos gestores públicos. Salienta-se também a possibilidade do aumento de precisão do modelo 
por meio da criação de novas regras, além das utilizadas, bem como a definição de diferentes pesos para as mesmas.

Em complemento, os valores inseridos no sistema possuem como base os limites fiscais, bem como, a LRF não prevê a possibilidade das contas públicas municipais serem parcialmente aprovadas ou reprovadas, conforme rege a lógica clássica, o sistema pode ser redesenhado para ser uma ferramenta de auxílio aos gestores públicos municipais. Desse modo os gestores podem agir para que as contas se enquadrem com antecedência nos limites previstos em lei. Assim, auxiliaria do mesmo modo, como o alerta que já é estabelecido pela LRF em seu artigo 22, § único, concernente aos cuidados que o gestor deverá ter quando o gasto da despesa com pessoal exceder $95 \%$.

Acrescenta-se que, em momentos econômicos nos quais a União e os Estados, principais repassadores de recursos aos municípios, se utilizam de instrumentos como desoneraçóes fiscais, por exemplo, como forma de estimular a economia, acabam por, em muitos casos, penalizando as contas dos municípios, levando-os a priorizar investimentos/ cortes em determinadas áreas. Assim, o modelo proposto também pode ser facilmente ajustado para incorporar estes momentos econômicos e possivelmente avaliaria as contas destes municípios de forma mais adequada.

Por fim, espera-se que o presente estudo possa contribuir para a ciência contábil e mais especificamente para a contabilidade pública, à medida que procurou demonstrar a aplicação de um modelo que não repousa sobre a lógica clássica. Naturalmente, por sua proposta inovadora, como pelo modelo gerado se torna nítida a demanda de novas pesquisas e o envolvimento de mais pesquisadores da área contábil, em especial com a utilização de cenários reais de enquadramento das contas públicas municipais.

Recomenda-se para futuras pesquisas a aplicação do modelo em uma amostra de municípios, permitindo avaliar se os cenários de aprovação ou rejeição de contas se altera significativamente.

\section{REFERÊNCIAS}

ANDRADE, M.; JACQUES, M.A.P. Estudo comparativo de controladores de Mamdani e Sugeno para controle do tráfego em interseçóes isoladas. Transportes, Rio de Janeiro, v.16, n.2, p.24-31, 2008.

ANTUNES, J. Lógica Nebulosa para Avaliar Riscos na Auditoria. Revista Contabilidade \& Finanças (Impresso), v.3, p.80-91, 2006.

BOJADZIEV, G.; BOJADZIEV, M. Fuzzy logic for bussiness, finance and management. Singapore: World Scientific, 1997.

BORBA, J.A.B.; DILL, R.P. Análise de rentabilidade de empresas: uma abordagem baseada na lógica nebulosa (Fuzzy logic). RAC-eletronica, São Paulo, v. 1, 2007. 
BRASIL. Constituição da República Federativa do Brasil: 1988. 23. ed. Brasília: Câmara dos Deputados, Coordenação de Publicações, 2004.

BRASIL. Lei Complementar no 101/2000, de 04 de maio de 2000. Estabelece normas de finanças públicas voltadas para a responsabilidade na gestão fiscal e dá outras providências. Disponível em: http://www.planalto.gov.br/CCIVIL/Leis/LCP/Lcp101. htm. Acesso em: 05 jul de 2008.

CHESLEY, G.R. Interpretation of uncertainty expressions. Contemporary Accounting Research, v.2, n 2, p.179-199, 1986.

COMUNALE, C.L.; ROSNER, R.L.; SEXTON, T.R. The auditor's assessment of fraud risk: A fuzzy logic approach. Journal of Forensic \& Investigative Accounting, v.3, n.1, p.149-194, 2010.

Conselho Federal de Contabilidade - CFC. Resoluçáo CFC nº 1.133, de 21 de novembro de 2008. Aprova a NBC T 16.6 - Demonstrações contábeis. Disponível em: http://www.cfc.org.br/sisweb/sre/detalhes_sre.aspx?Codigo=2008/001133. Acesso em: 05 mai. 2009.

COOLEY, J.W.; HICKS, J.O. A fuzzy set approach to aggregating internal control judgments. Management Science, v.29, n.3, p.317-334, 1983.

DESHMUKH, A.; ROMINE, J. Assessing the risk of management fraud using red flags: a fuzzy number based spreadsheet approach. Journal of Accounting and Computers, v.4, n3, p. 5-15, 1998.

DESHMUKH, A.; TALLURU, L. A fuzzy set approach to client acceptance decisions. Applications of fuzzy sets and the theory of evidence to accounting, II. Stanford: JAI Press, 1998.

DILL, R.P.; COSTA JR.; N.C.A.; SANTOS, A.A.P. Paraconsistent and fuzzy logic applied to company profitability analysis. Economics Bulletin, v.33, p.1348-1360, 2013.

DILL, R.P.; DA COSTA JR., N., SANTOS, A.A.P.: Corporate Profitability Analysis: A Novel Application for Paraconsistent Logic. Applied Mathematical Sciences, v.8, p.1271-1288, 2014.

FRIEDLOB, G.T.; SCHLEIFER, L.L.F. Fuzzy logic: application for auditing risk and uncertainty. Managerial Auditing Journal, v.14, n.3, p.127-137, 1999.

HAJIHAA, Z. Fuzzy audit risk modeling algorithm. Management Science Letters, v.1, n.3, p.235-246, 2011.

KOHAMA, H.. Contabilidade pública: teoria e prática. 9. ed. São Paulo: Atlas, 2003. 
KORVIN, A.; SIEGEL, P.; STRAWSER, J. An application of control system to cost variance analysis. Managerial Finance, v.21, n.3, p.17-36, 1998.

LIN, H.C.; LIN, F.C.; HSIAO, T.Y.; LIN Y.C. Fuzzy set theory in managerial contract analyses, Expert Systems with Applications, v.36, p.4535-4540, 2009.

LIN, J.W.; HWANG, M.I.; BECKER, J.D. A fuzzy neural network for accessing the risk of fraudulent financial reporting. Managerial Auditing Journal, v.18, n.8, p.657-665, 2003.

SAI, F. Applying Fuzzy Outranking Method to Measurement System of Multidimensional Performance, Procedia. Social and Behavioral Sciences, v.25, p.345-352, 2011.

Senado Federal. Resoluçáo no 40, de 2001. Dispóe sobre os limites globais para o montante da dívida pública consolidada e da dívida pública mobiliária dos Estados, do Distrito Federal e dos Municípios, em atendimento ao disposto no art. 52, VI e IX, da Constituiçãa Federal. Disponível em: http://www6.senado.gov.br/sicon/ PreparaPesquisaLegislacao.action. Acesso em: 01 jul. 2009.

SERGUIEVA, A.; HUNTER, J. Fuzzy interval methods in investment risk appraisal. Fuzzy Sets and Systems, v.142, n.3, p.443-466, 2004.

SHAW, I.S.; SIMÕES, M.G. Controle e Modelagem Fuzzy. São Paulo: Edgard Blücher, 2001.

SIEGEL, P.H.; KORVIN, A.; OMER, K. Applications of fuzzy sets and the theory of evidence to accounting. Stanford: JAI Press, 1998.

SLOMSKI, V. Manual de contabilidade pública: um enfoque na contabilidade municipal, de acordo com a Lei de Responsabilidade Fiscal. São Paulo: Atlas, 2001.

Controladoria e governança na gestão pública. São Paulo: Atlas, 2005.

SÖTHE, A. Diretrizes do IFAC para o regime de competência: impactos nos resultados contábeis dos governos municipais da microrregiáo de Sáo Miguel do Oeste - SC. 2009. 147 f. Dissertação (Mestrado em Ciências Contábeis) - Programa de Pós-Graduação em Ciências Contábeis da Universidade Regional de Blumenau, Blumenau, 2009.

SYAU, Y.R.; HSIEH, H.T.; LEE, S. Fuzzy numbers in the credit rating of enterprise financial condition. Review of Quantitative Finance and Accounting, v.17, n.4, p.351360, 2001.

VON ALTROCK, C. Fuzzy logic and neuroFuzzy applications in business and finance. New Jersey: Prentice Hall, 1995. 
ZADEH, L.A. Fuzzy sets. Information and Control, v.8, n.3, p.338-353, 1965.

ZEBDA, A. The investigation of cost variances: a fuzzy set theory approach. Decision Sciences, v.15, n.3, p.359-389, 1984.

ZEBDA, A. Problem of ambiguity and vagueness in accounting. Behavioral Research in Accounting, v.3, p.117-145, 1991. 